\title{
Seafloor massive sulfide deposits from the Juan de Fuca Ridge: evidence from multiple sulfur isotopes for buried sediment and microbial activity
}

SARAH MORIARTY ${ }^{1 *}$ EMMA BERTRAN ${ }^{2}$, JAMES DOTTIN III $^{3}$, JOHN JAMIESON ${ }^{1}$, DAVID JOHNSTON ${ }^{4}$, JAMES FARQUHAR $^{3}$, MARGARET TIVEY ${ }^{5}$ AND STEPHEN PIERCEY ${ }^{1}$

${ }^{1}$ Department of Earth Sciences, Memorial University of Newfoundland, St. John's, NL A1B 3X7, Canada (*Correspondence: snmoriarty@mun.ca)

${ }^{2}$ Princeton Environmental Institute, Princeton University, Princeton, NJ 08544, USA

${ }^{3}$ Department of Geology, University of Maryland, College Park, MD 20742, USA

${ }^{4}$ Department of Earth and Planetary Sciences, Harvard University, Cambridge, MA 02138, USA

${ }^{5}$ Woods Hole Oceanographic Institution, Woods Hole, MA 02543, USA

The Juan de Fuca Ridge (JdFR), a spreading center located off the west coast of North America, contains both sediment-free and sediment-hosted hydrothermal systems (Axial volcano and Middle Valley, respectively). At many sediment-free mid-ocean ridge hydrothermal systems, seafloor massive sulfide (SMS) deposits are relatively small, as a large percentage of hot, metal rich vent fluids are entrained in hydrothermal plumes and dispersed into the water column. At sediment-hosted sites, seawater infiltration and subsurface fluid mixing are more prevalent, resulting in significant subseafloor mineral precipitation. The Endeavour vent field, which is also located on the JdFR, occurs at the extent of turbiditic sedimentation, and evidence from vent fluid chemistry suggests the presence of buried sediment beneath the currently sediment-free basalt flows $[1,2]$.

In this study we use multiple sulfur isotope ratios of hydrothermal precipitates from these three sites to isotopically fingerprint differences in hydrothermal sulfur cycling associated with sedimented and sediment-free substrates. We present a three-component mixing model in $\Delta^{33} \mathrm{~S}$ and $\delta^{34} \mathrm{~S}$ space that represents the differing contributions of sulfur derived from seawater, magmatic sources, and both sediment and crustal sulfur sources that have been influenced by microbial activity.

[1] Lilley et al. (1993) Nature 364, 45-47. [2] You et al. (1994) EPSL 123, 227-238. 